\title{
Glycans in nanomedicine, impact and perspectives
}

\author{
Susanna Sampaolesi ${ }^{1}$, Francesco Nicotra ${ }^{1}$ \& Laura Russo*,1 \\ ${ }^{1}$ Department of Biotechnology \& Biosciences, University of Milano-Bicocca, Piazza della Scienza 2, 20126 Milan, Italy \\ *Author for correspondence: laura.russo@unimib.it
}

Glycans have been selected by nature for both structural and 'recognition' purposes. Taking inspiration from nature, nanomedicine exploits glycans not only as structural constituents of nanoparticles and nanostructured biomaterials but also as selective interactors of such glyco-nanotools. Surface glycosylation of nanoparticles finds application in targeting specific cells, whereas recent findings give evidence that the glycan content of cell microenvironment is able to induce the cell fate. This review will highlight the role of glycans in nanomedicine, schematizing the different uses and roles in drug-delivery systems and in biomaterials for regenerative medicine.

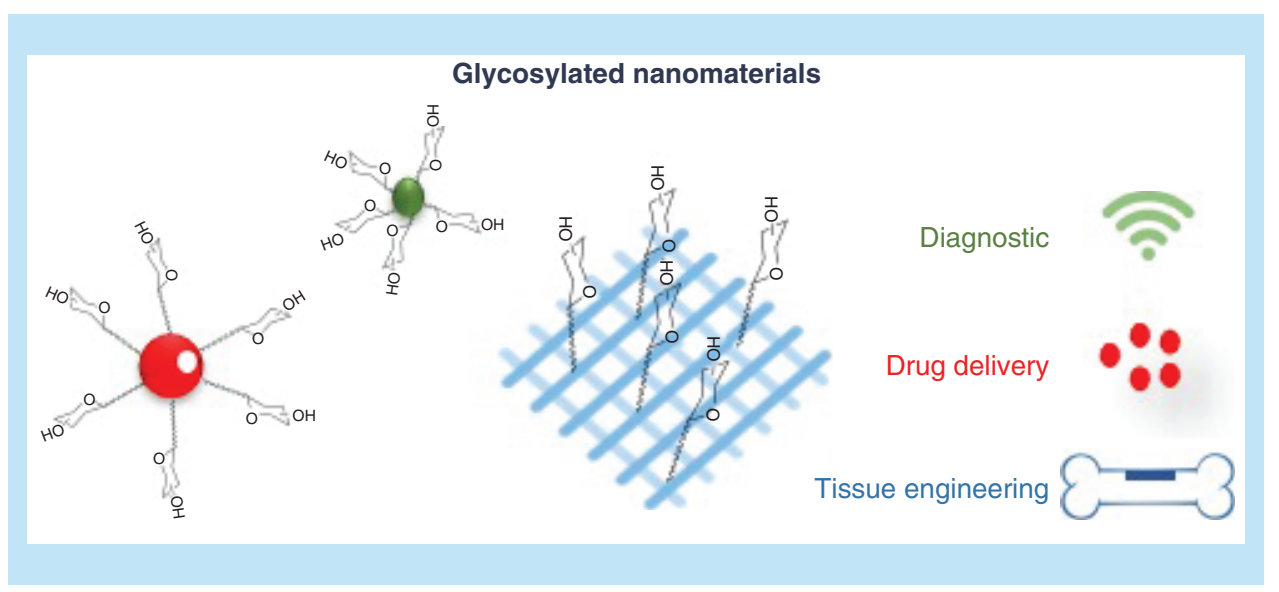

First draft submitted: 1 August 2018; Accepted for publication: 5 November 2018; Published online: 11 December 2018

Keywords: biomaterials $\bullet$ drug delivery $\bullet$ glycans $\bullet$ nanoparticles $\bullet$ regenerative medicine

Nanomedicine is divided into two main branches, nanoparticles and nanostructured materials, developed for biomedical applications. Nanoparticles are exploited for drug delivery and diagnosis, taking advantage of their peculiar kinetic behavior in the body, and the capacity to load drugs or diagnostics. In other words, nanoparticles find attractive applications in biomedicine for their 'dynamism' that makes them as 'magic bullets' to reach a biological target (Figure 1A). Nanostructured materials, on the contrary, are bulky and static, the term 'nano' refers to their structural organization that is nanometric (Figure 1B).

Nanostructured materials are generated to mimic tissues, bones and even organs, and the main application is therefore in regenerative medicine, the term biomaterial is generally used. Biomaterials find application also for homing cells and inducing cell fates.

In both nanoparticles and biomaterials, biocompatibility is the first requirement. Materials with poor biocompatibility will be cleared very soon by the immune system. Some 'well accepted' biocompatible materials, however, can interact with the immune system stimulating undesired immunomodulatory effects (immunosuppression or immunomodulation) after repeated administration (such as PEGylated nanoparticles). 


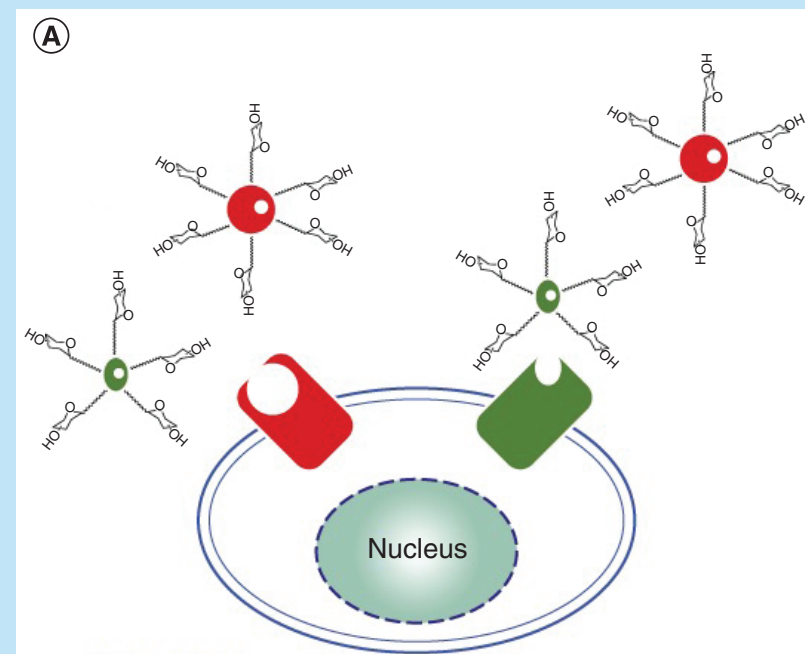

(B)

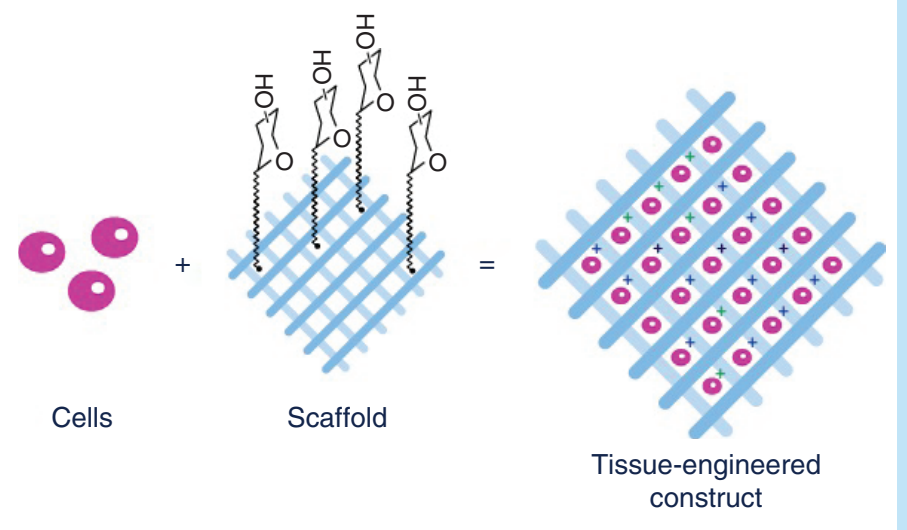

Extracellular matrix

Figure 1. Nanomedicine tools. (A) Nanoparticles for drug-delivery and diagnosis and (B) nanostructured biomaterials for cell culture and tissue engineering.

Nanoparticles for drug delivery require materials able to assemble in nanometric entities (usually 50-200 nm), to load drugs and release them at the pathological site. Molecular interactions, mainly hydrophobic, are exploited in this process. Liposomes are the most significant example and the first nanoparticles generated for drug delivery in the 1970s [1-3] and the first nanodrug approved by the US FDA in 1995, Doxyl ${ }^{\circledR}$, is a formulation of liposomes incorporating the antitumor agent doxorubicin. Changes of $\mathrm{pH}$ or other chemophysical stimuli at the pathological site will cause the nanoparticle collapse and the release of the drug [4]. For diagnostic purposes, the collapse of the nanoparticle is not needed, and therefore their structure can be stable. Magnetic nanoparticles [5] or gold nanoparticles [6] are some examples of diagnostic nanoparticles, taking advantage of their magnetic or photonic behavior.

Nanostructured biomaterials have different requirements depending on their final applications. They must be rigid and stable in bone implants, or soft and biodegradable as temporary matrices for tissue regeneration.

Nature is an invaluable font of inspiration; natural materials are mainly composed of carbohydrates and proteins. Therefore, scientists largely explored the possibility to use polysaccharides and polypeptides to generate both nanoparticles and biomaterials. This review will concentrate mainly on the role and perspective of glycans in nanomedicine, therefore, we will treat proteins only marginally.

\section{Glycan-based nanoparticles}

Chitin from shellfish is an example of material with robust structure; alginates from algae are examples of elastic solid natural hydrogels; hyaluronic acid (HA), found in connective tissues, is an example of viscous, highly hydrophilic material.

Combination of polysaccharides with opposite charges (anionic and cationic) allows you to generate nanoparticles via polyelectrolyte complexation [7]. Examples of charged polysaccharides forming nanoparticles by intermolecular electrostatic interaction (Figure 2) are: chitosan, obtained from chitin deacetylation; heparin, the anticoagulant polysaccharide isolated from slathered meat animals such as porcine intestines or bovine lungs; $\mathrm{HA}$, articular cartilage component widely used in cosmetics; chondroitin sulfate (CS), natural component of proteoglycans, extracted for example from cartilaginous cow and pig tissues; pectin, a natural polysaccharide isolated from vegetables and fruits used also in food industry; alginate, widely distributed in the cell wall of brown seaweeds from which is isolated.

Charged polysaccharides can be obtained by derivatization of some hydroxyl groups of a neutral polysaccharide with a negatively charged functional group, such as a sulfate, or a positively charged molecular entity, such as a quaternary ammonium salt. For this purpose, different $\alpha$-D-glucoside polymers have been exploited by taking 


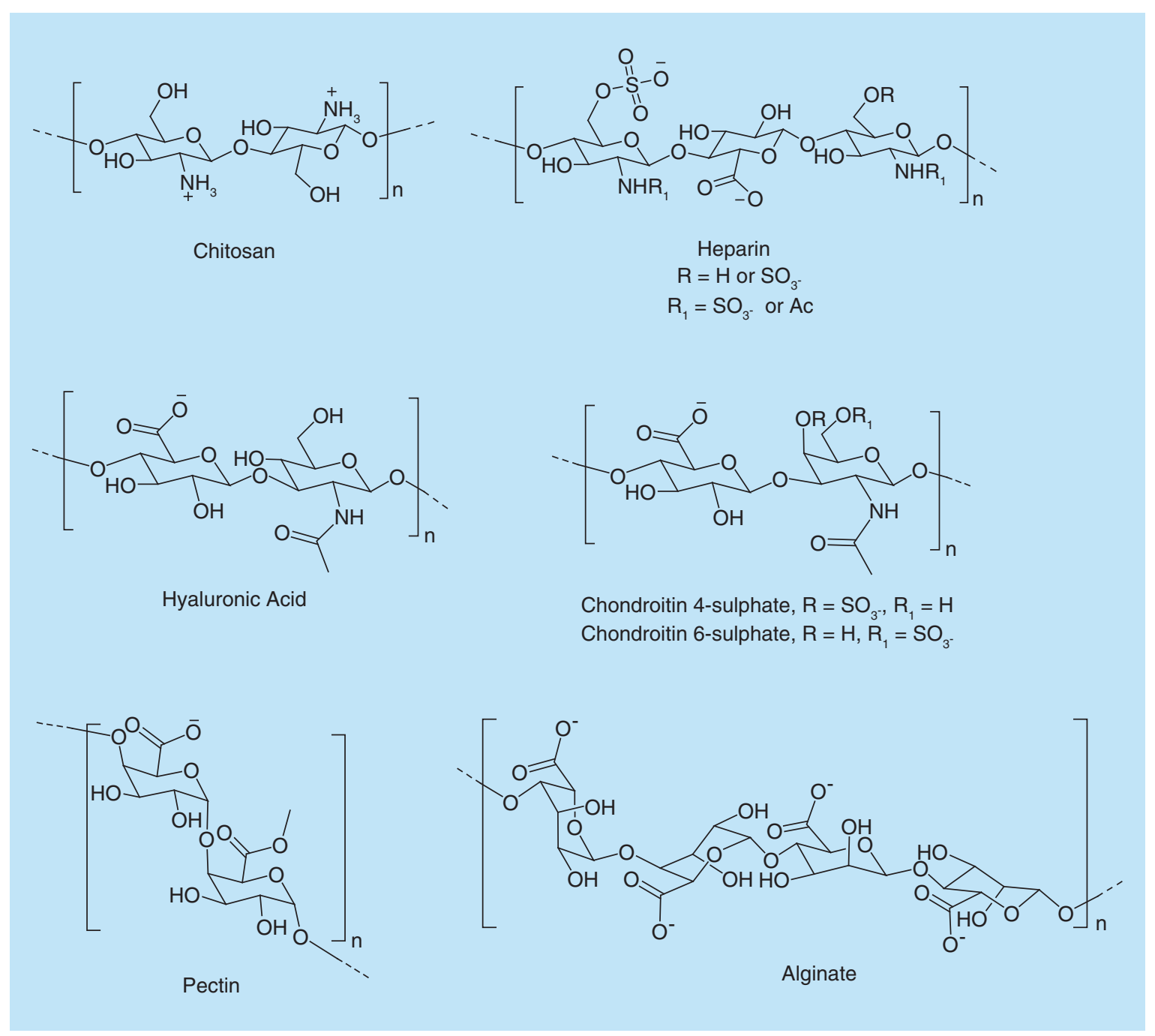

Figure 2. Structure of charged polysaccharides.

advantage of their biocompatibility and biodegradability. Starch is not really suitable for this purpose, it must be significantly modified to provide it the required consistency [8,9]. Dextran, a branched $\alpha$-D-glucoside polymer obtained by microbial fermentation of sucrose, has been sulfated in order to obtain an anionic glycopolymer, and attached to spermine, generating a cationic polysaccharide. Pullulan, a polysaccharide of fungal origin composed by $\alpha-1,6-$ linked maltotriose units ( $\alpha-1,6-$ Glc- $\alpha-1,4-$ Glc- $\alpha-1,4-$ Glc- $\alpha-1,6-)$ has been also sulfated and aminated [10]

The interaction between the positively charged $\left[-\mathrm{NH}_{3}{ }^{+}\right.$or $\left.-\mathrm{NR}_{3}{ }^{+}\right]$and the negatively charged $\left[-\mathrm{COO}^{-}\right.$or $-\mathrm{OSO}_{3}{ }^{-}$] polysaccharides favors the aggregation that can be strengthened by proper cross-linking, in order to provide the required nanoparticle stability. In Table 1, some of charged polysaccharides (natural and semisynthetic) employed in the generation of nanoparticles.

Chitosan, obtained by deacetylation of chitin, is one of the most widely used and commercially available positively charged polysaccharides. The deacetylation is often incomplete and it changes from batch to batch. The amino groups provide cationic character once protonated, therefore, the combination of chitosan with other polymers containing carboxylates or sulfates, results in the formation of salts in which the Coulombian forces generate aggregates.

Chitosan-HA nanoparticles have been widely synthesized and tested for treatment of many pathologies such as cancer [28], asthma [29], osteoarthritis [30], and for ocular therapy [31]. 
Table 1. Examples of polysaccharides used to generate nanoparticles for biomedical applications.

\begin{tabular}{|llrr|}
\hline Polysaccharide & Anionic/cationic & Natural/semisynthetic & Ref. \\
\hline Chitosan & + & Natural & [11-13] \\
\hline Alginate & - & Natural & Natural \\
\hline Hyaluronic acid & - & Natural & {$[14]$} \\
\hline Heparin & - & Natural & {$[17,18]$} \\
\hline Chondroitin sulfate & - & Semisynthetic & {$[19-21]$} \\
\hline Pectin & - & Semisynthetic & {$[22-24]$} \\
\hline Dextran-spermine & + & Semisynthetic & {$[10,25]$} \\
\hline Dextran sulfate & - & Semisynthetic & {$[10]$} \\
\hline Pullulan sulfate & - & Semisynthetic & {$[10]$} \\
\hline Aminated pullulan & + & {$[10,26,27]$} \\
\hline Pullulan-betaine & + & & \\
\hline
\end{tabular}

Chitosan-dextran sulfate nanoparticles are another example of nanocarriers generated by assembling positively and negatively charged polysaccharides. They have been proposed for delivery of antiangiogenetic peptides [32], in bones regeneration [33], for ocular delivery [34].

Chitosan-alginate nanoparticles are particularly effective for the delivery of insulin [35], antisense oligonucleotides [36], diclofenac [37].

Chitosan-heparin nanoparticles, prepared by polyelectrolyte complexation [38], have been developed for stomach specific anti-Helicobacter pylori therapy [39,40], and to load antitumor agents such as paclitaxel [41].

Chitosan-CS nanoparticles have been exploited for controlled release of platelet lysates for bone regenerative medicine [42], and to release in a controlled way the antitumor drug doxorubicin [43].

Chitosan-pectin nanoparticles have been generated and characterized [44,45], but did not found any significant application in drug delivery.

Dextran, $[\rightarrow 6)-\alpha$-D-glucopyranosyl- $(1 \rightarrow 6)-\alpha$-D-glucopyranosyl- $(1 \rightarrow]$, has been functionalized with quaternary ammonium salts to generate cationic polysaccharides. The functionalization can be performed by partial periodate cleavage of the vicinal diols of the sugar, and subsequent reductive amination of the obtained aldehydes with spermine and $\mathrm{NaBH}_{4}$ (Figure 3A). Dextran-spermine is an example of modified polysaccharide widely exploited to generate nanoparticles mainly utilized for gene transfection [23], but also to deliver doxorubicin in breast cancer cells [24]. Pullulan $[\rightarrow \mathrm{x})-\alpha$-D-glucopyranosyl-( $1 \rightarrow 4)-\alpha$-D-glucopyranosyl- $(1 \rightarrow]$ and $[\rightarrow 4)-\alpha$-Dglucopyranosyl-( $1 \rightarrow 6)$ - $\alpha$-D-glucopyranosyl- $(1 \rightarrow]$, where $\mathrm{x}$ may be either 4 or 6 for $(1 \rightarrow 4)$ linked segment, is another biocompatible and biodegradable polysaccharide suitable to generate nanoparticles. For this purpose, it has been sulfated, creating an anionic polymer or conjugated to a quaternary ammonium salt [10] (Figure 3B) or even with cholesterol [27].

The massiveness versus the capacity to collapse in specific environmental conditions ( $\mathrm{pH}$, temperature, redox) or with specific external stimuli, must be carefully balanced. This is possible not only dosing the hydrophobicity and the Coulombian interactions but also by proper cross-linking. Cross-linking strategies can exploit ionic interactions or covalent bonds. An example of cross-linking with ionic interactions is the methodology to generate chitosan nanoparticles with pentasodium triphosphate [46]. Covalent cross-linking, obviously much more stable, exploits bifunctional linkers able to conjugate different polymeric chains. Interestingly, there is the possibility to use bioresponsive linkers the chain of which can be cleaved in proper conditions; in this case, the collapse of the nanoparticle will be a consequence of this cleavage $[47,48]$.

\section{Glycan-coated nanoparticles}

Nanoparticles for therapeutic and diagnostic purposes have been extensively decorated at the surface with glycans [49], in order to render them more biocompatible and to provide them with interactive properties. With these aims, glycan-coated nanoparticles have been exploited either to generate nanoparticles stealth to the immune system or to target specific carbohydrate-recognizing receptors.

Nanoparticles can induce immune response-activating phagocytic cells that will eliminate them from the circulation, or inducing immunostimulation which may promote inflammatory disorders, or even immunosuppression increasing the host's susceptibility to infections and cancer [50]. To avoid this phenomenon, they must be coated 
(A)
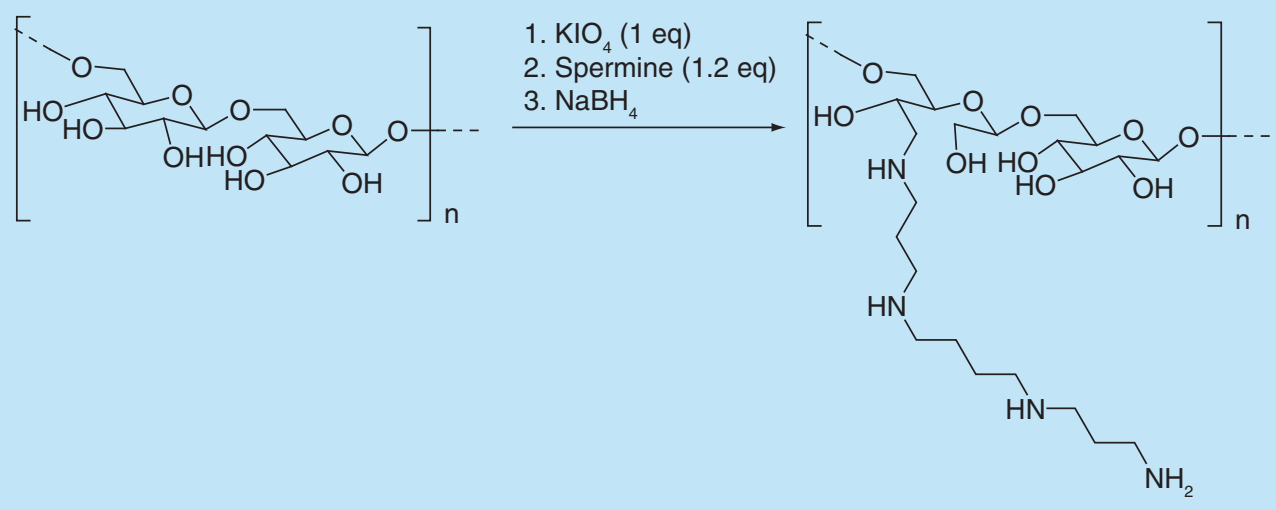

(B)
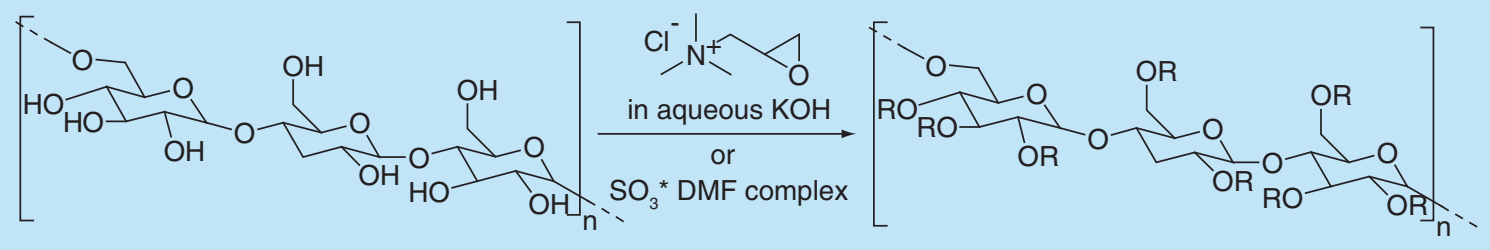

$$
\mathrm{R}=\mathrm{SO}_{3}^{-} \mathrm{Na}^{+} / \mathrm{H}
$$

or

$\mathrm{R}=\mathrm{CH}_{2} \mathrm{CH}(\mathrm{OH}) \mathrm{CH}_{2} \mathrm{~N}^{+}\left(\mathrm{CH}_{3}\right)_{3} \mathrm{Cl} / \mathrm{H}$

Figure 3. Dextran-spermine modification to generate nanoparticles with delivery purpose.

with molecules that make them stealth to the immune system. The most used strategy for this purpose is to coat the nanoparticle with PEG chains, although extended treatment with PEGylated nanoparticles elicited anti-PEG IgM response in a T-cell independent manner [51]. Carbohydrates provide a stealth layer to nanoparticles without compromising their cellular uptake. A liposome formulation generated with monosialotetrahexosylgangloside GM1 as component, and therefore presenting glycans at the surface, exhibited a prolonged circulation time in blood avoiding spleen and liver uptake [52]. Dextran has shown significant efficacy to make the nanoparticles stealth. It was mainly used to coat iron oxide nanoparticles [53], widely studied for diagnostic imaging by MRI and for thermotherapy [54]. Dextran-coated gold nanoparticles have been studied as antibacterial agents [55] and as a doxorubicin-delivery system [56]. Dextran-coated gadolinium-phosphate nanoparticles have been also generated and tested for magnetic resonance tumor imaging [57]. It has been observed that Ag nanoparticles functionalized with galactose and mannose were significantly less toxic to neuronal-like cells and hepatocytes with respect to those coated with glucose. It has been also noticed that the toxicity was correlated to oxidative stress but not to cellular uptake. In perspective, there is a general belief that decoration of nanoparticles with not immunogenic glycans will provide stealth properties to the nanoparticles. On the other hand, glycans can interact with numerous receptors expressed by different cells of diverse tissues, with extracellular proteins and circulating antibodies.

\section{Targeting with glycan-decorated nanoparticles}

Glycans mediate a multitude of recognition phenomena that are responsible for a variety of physiologically and pathologically relevant biomolecular processes. Table 2 summarize some example of correlation between physiological and pathological events and specific glycans. The glycocode represents one of the most important and complex actors in the regulation and dysregulation of physiological state in biological systems. In particular, glycan diversity acts as dynamic regulator of pathological events and involves several mechanisms that cover a multitude of cell processes. Here, we will make just few examples of glycans involvement in pathological events. 
Table 2. Selected examples of sugar epitopes and parent receptors.

\begin{tabular}{|c|c|c|c|}
\hline Glycan & Receptor & Target & Refs. of gly-NPs \\
\hline$\alpha-\operatorname{Man}$ & C-type lectin & (Macrophages) immune response & [62-64] \\
\hline$\beta$-Gal & Gal & Liver, tumor & [65-67] \\
\hline$\alpha$-Fuc & DC-SIGN & Immune system & [68] \\
\hline$\alpha-G l c$ & GLUT & Glioma & [69] \\
\hline Oligo- $\alpha$-Man & Gp120 & HIV-1 & [70] \\
\hline $\begin{array}{l}\text { Sialyl Lewis } x \\
\text { Neu5acc } \alpha 2-3-G a l-\beta 1-4 G I c N A c \\
\text { Fuc } \alpha 1-3\end{array}$ & $\begin{array}{l}\text { CD62E, } \\
\text { CD62P }\end{array}$ & Inflammation & [71] \\
\hline Neu5ac $\alpha 2-6$ Gal $\beta \quad 1-4$ GIcNAc & $\mathrm{CD}-22$ & $\begin{array}{l}\text { B cells, autoimmune disorders and } \\
\text { cancer }\end{array}$ & [72] \\
\hline Neu5ac $\alpha 2-3-G a l \beta 1-4 G \mid c-$ & & Enterotoxigenic E. coli 13762 & [69] \\
\hline $\begin{array}{l}\text { TF tumor antigen } \\
\text { Gal } \beta 1-3 \text { GalNAc- } \alpha-\end{array}$ & & Tumor vaccines & [73] \\
\hline $\begin{array}{l}\text { Lewis } x \\
\text { Gal- } \beta 1-4 \text { GICNAC } \\
\text { Fuc } \alpha 1-3\end{array}$ & DC-SIGN & Antitumor immune response & [74] \\
\hline $\begin{array}{l}\text { Lewis a } \\
\text { Gal- } \beta 1-3 \text { GIcNAc } \\
\text { Fuc } \alpha 1-4\end{array}$ & $\begin{array}{l}\text { DC-SIGN } \\
\text { SIGN-R1 }\end{array}$ & Antitumor immune response & [76] \\
\hline $\begin{array}{l}\text { Lewis b } \\
\text { Fuc } \alpha 1-2 \text { Gal- } \beta 1-3 \text { GIcNAC } \\
\text { Fuc } \alpha 1-4\end{array}$ & BadA & Helicobacter pylori & [74] \\
\hline $\begin{array}{l}\text { H type } \\
\text { Fuc } \alpha 1-2 \text { Gal- } \beta 1-3 G I c N A c\end{array}$ & $\begin{array}{l}\text { DC-SIGN } \\
\text { SIGN-R1 }\end{array}$ & Antitumor immune response & [74] \\
\hline
\end{tabular}

GLUT: Glucose transporter; NP: nanoparticle.

Glycans, for example, are extensively investigated for their involvement in tumor progression. Today is well know that altered glycan structures (tumor-associated antigens) are strongly involved in dysregulated mechanisms that are at the basis of tumor development and progression [58]. Also other pathological conditions are mediated by altered glycan structures that interact with specific glycan-binding proteins on cell surface or in the extracellular space. For example, mannose receptors are abundant in macrophages and they are involved in host defense [59]. Galactose receptors are highly expressed on hepatocytes and liver macrophages, where they are specifically involved in mediation of endocytosis mechanism [60], and in many tumors overexpressing Gal-3 [61].

As listed in Table 2, some examples of signaling glycans can be simple monosaccharides, also if in the major part of cases the interaction with parental receptor can be governed by multivalency. Signaling events can involve also linear or branched oligosaccharides (Figure 4). Thanks to the diversity in their structure and conformation, in their glycan epitopes content and variation of glycosidic linkages, these oligosaccharides are more versatile in their interaction with different glycan-binding proteins that result in tuning of cell signaling.

Magnetic nanoparticles decorated with D-Glucose and D-Galactose were tested for their capacity to be internalized by Vero cells (monkey kidney epithelial cells). The results clearly indicate that both Glc- and Gal-decorated NPs were internalized, but with different cellular distribution and kinetics. In fact, Glc-decorated NPs enter throughout the cell into the cytoplasm after $15 \mathrm{~min}$, whereas Gal-NPs remain predominantly on the cell periphery, or attached to the membrane [77]. 2-Deoxy-D-glucose decorated NPs have been exploited to facilitate the transport through the blood-brain barrier, and the internalization in glioma cells, both overexpressing the glucose transporter [78].

Liposomes decorated with alpha 2-6-linked sialylated glycans have been experimented to target the CD22 receptor in B-cell lymphoma. The results of this study demonstrate that targeting strategy based on carbohydrates represents an efficient method to improve available treatments for B-cell malignancies [79].

Magnetic glyco-nanoparticles decorated with different tumor-associated glycans have been exploited as a tool to detect cancer cells via MRI [80]. Such magnetic glyco-nanoparticles have been also used for hyperthermal therapy in tumors $[81,82]$. 


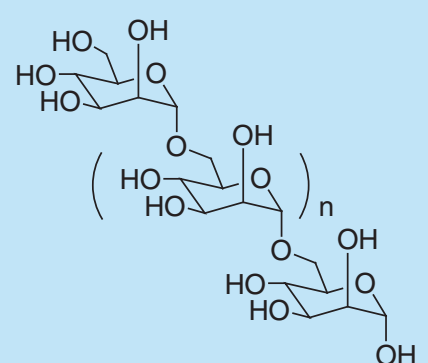

Oligo- $\alpha-M a n$

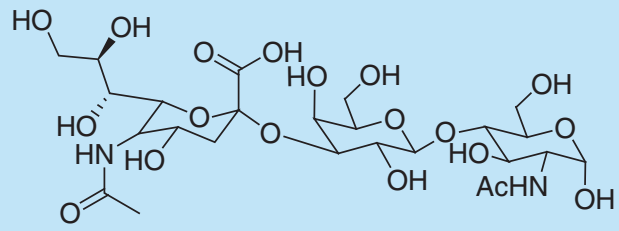

Neu5Aco2-3-Galß1-4GlcNac

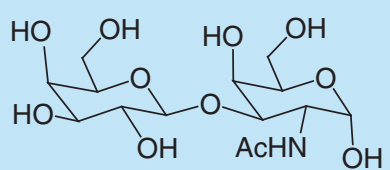

TF Tumor Antigen

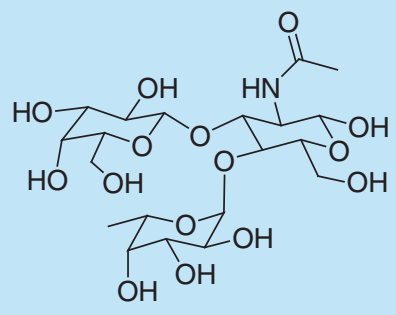

Lewis a

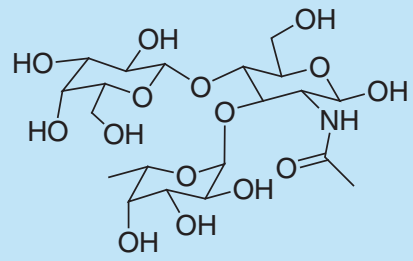

Lewis $\mathrm{x}$

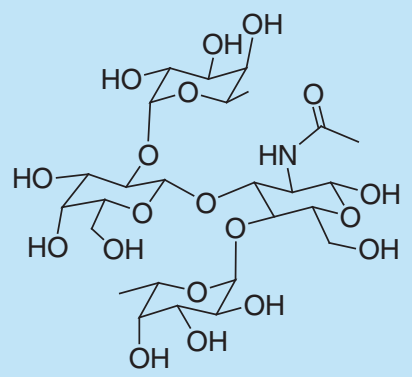

Lewis b

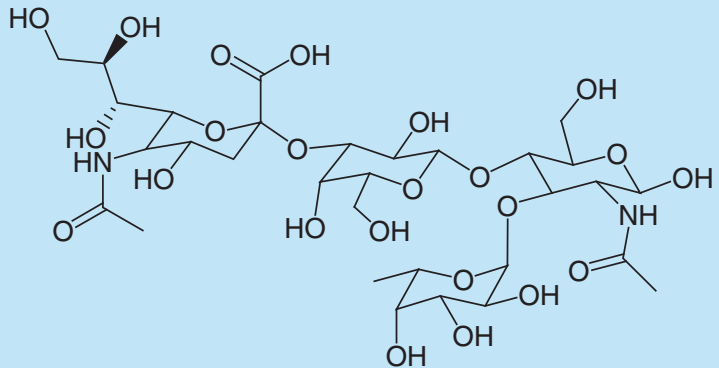

Sialyl Lewis $\mathrm{x}$

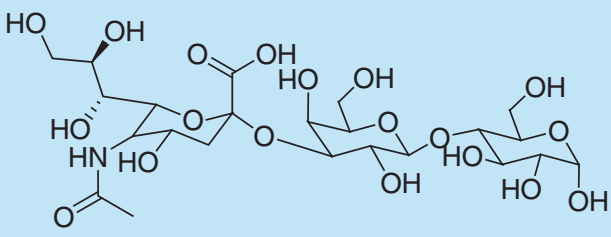

Neu5Ac $\alpha 2-3-G a l \beta 1-4 G l c-$

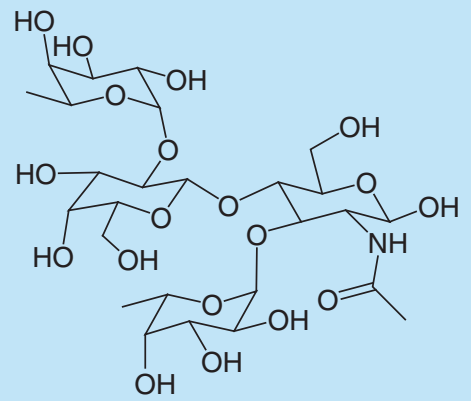

Lewis y

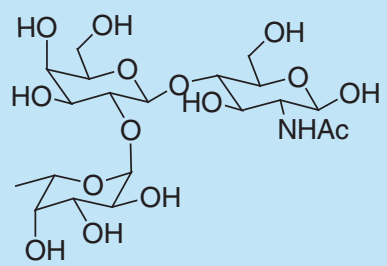

H Type

Figure 4. Some signaling glycans.

\section{Glyco-biomaterials}

Nanostructured materials for biomedical applications, also defined biomaterials, require specific properties depending on the applications. Rigid materials find application for hard tissue replacement (bones), whereas hydrogels are useful for soft tissue repair and for cell cultures. Biocompatibility and eventually controlled biodegradability are other required properties. Some polysaccharides meet these requirements and therefore found wide application as biomaterials for regenerative medicine. Several examples of polysaccharide-based biomaterials were developed for 


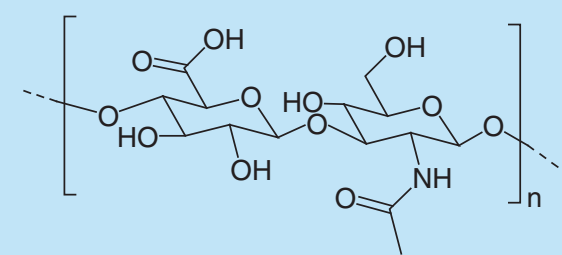

Hyaluronic Acid

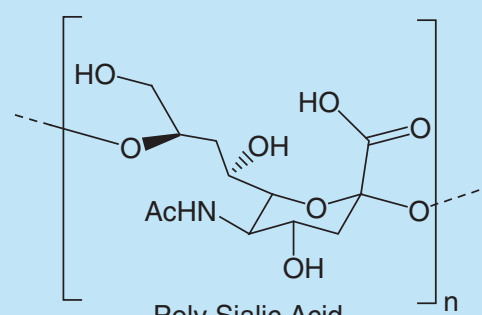

Poly Sialic Acid

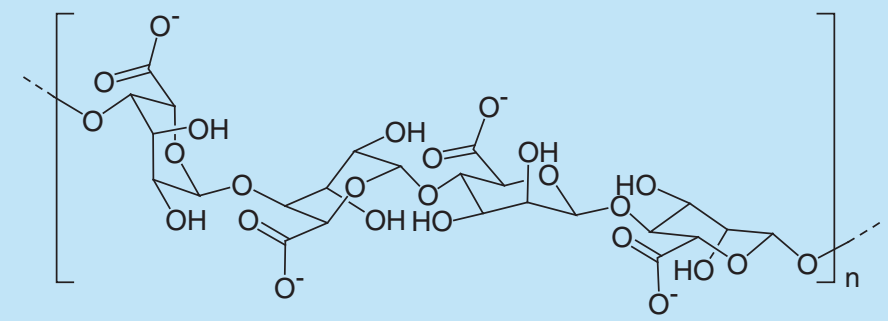

Alginate

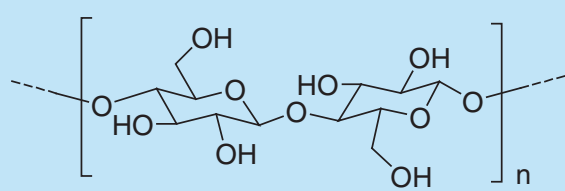

Cellulose

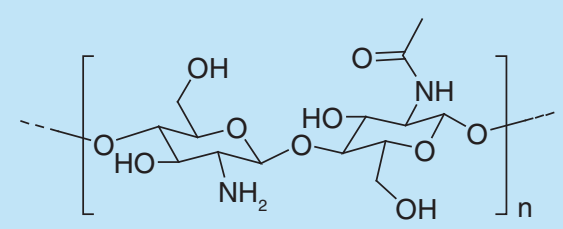

Chitosan

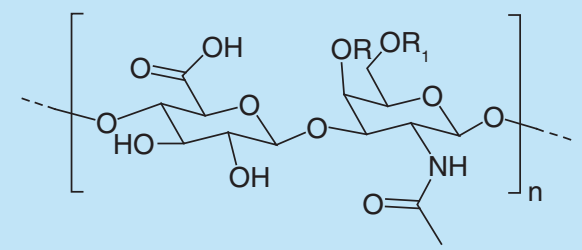

Chondroitin 4-sulphate, $\mathrm{R}=\mathrm{SO}_{3}, \mathrm{R}_{1}=\mathrm{H}$ Chondroitin 6-sulphate, $\mathrm{R}=\mathrm{H}, \mathrm{R}_{1}=\mathrm{SO}_{3}$.

Figure 5. Examples of polysaccharides employed in tissue engineering.

\section{Table 3. Commonly used polysaccharides for biomedical applications in regenerative medicine.}

Polysaccharide

Cellulose

Chitosan

GAG

Hyaluronic acid

Chondroitin sulfate

Alginates Applications

Bone and tissue regeneration, cell delivery

Bone and cartilage regeneration, wound healing, cell delivery

Osteochondral regeneration, skin regeneration, heart

valves, $2 \mathrm{D} / 3 \mathrm{D}$ cell culture models, ECM mimics

Cell delivery, 2D, 3D ECM mimics [108-115]

Cell delivery, ECM mimics

$[116,117]$

Bone regeneration, nerve regeneration, bone marrow cells culture, pancreatic islets encapsulation

Polysialic acid

Cell culture models, peripheral nerve regeneration

ECM: Extracellular matrix; GAG: Glucosaminoglycan.

cartilage and bone tissue engineering applications, as well as extracellular matrix (ECM) mimetics for 3D and 3D cell culture studies. The most used polysaccharides are HA, chitosan, alginate, CS, polysialic acid (PSA) and in general glucosaminoglycans (GAGs; Figure 5).

The literature on this matter is extensive and has been reviewed [83-88]; our intent is to summarize and schematize; Table 3 reports the most relevant examples and their main applications. 
Natural polysaccharides have been widely used as biomaterials for regenerative medicine, modulating their properties by combination with other polysaccharides, or with ECM proteins or with hydroxyapatite, or even with synthetic polymers. Dosing the composition and the intensity of cross-linking, it was possible to generate a wide variety of biomaterials, the properties of which have been finely tuned for the different biomedical applications.

Cellulose offers high mechanical properties and improved osteoblast performance and therefore it has been studied for bone tissue regeneration applications [89,90]. It has been used also for screws to graft tendons to bones and to regenerate intervertebral discs. Interestingly, cellulose has been used also to produce hydrogels for cell delivery applications and nanofibers with excellent elastic modulus and tensile strength exploitable for several soft tissue regeneration applications [91,92].

Chitosan is largely used to generate hydrogels that find application in biomedicine [93-96]. Its properties can be easily modulated by cross-linking strategies involving the free amino groups [97]. Chitosan-based hydrogels have found applications to deliver cells by minimally invasive injection into the body [98] and for tissue healing, thanks to its unique hemostatic, analgesic and mucoadhesive properties, combined with antibacterial and antifungal activity [99,100]. Hybrid materials, containing chitosan in combination with polycaprolactone (PCL) and collagen have also been developed to improve the osteogenesis [101]. Even for bone tissue engineering, chitosan has been successfully integrated into sol-gel processes to obtain inorganic/organic hybrids with nanoscale conetworks that give them tailored mechanical properties and controlled biodegradation [102].

GAGs, among which heparin, found application in regenerative medicine as component of materials made by other biopolymers [103], in which the role of GAGs is to provide signals to the cells more than act as scaffold. Collagen-GAG biomaterials have been studied for their capacity to induce the cell fate [104,105], and in particular they have been investigated for heart valve tissue engineering applications [106]. In order to replace damaged tissues, GAGs-derived biomaterials can be composed by more than two components, for example, CS, HA and silk fibroin have been used to produce porous scaffolds for skin tissue engineering [107].

HA is a natural component of ECM providing lubrication of the articular joints and cartilage repair controlling chondrocyte proliferation, migration and differentiation [108]. The biological properties of HA strongly depend on its molecular weight and they can be even opposite. High-molecular weight HA shows antiangiogenic properties and inhibits cell proliferation [109], whereas short fragments are known to promote cell migration and angiogenesis [110]. Injectable formulations containing HA with bioceramics have been developed to induce bone formation [111]. HA has found wide application in regenerative medicine, mainly for cell delivery $[112,113]$ and interesting results have been obtained also in nerve regeneration [114]. Implantation of HA hydrogels in rat model of intervertebral disc injury results not just in a reduction of inflammation but also in prevention of the pain phenotype reducing also nociceptive behavior [115].

CS is another natural component of ECM, present in articular cartilage together with type II collagen and involved in various physiological and pathological functions such as cell morphogenesis and neuronal plasticity. In order to mimic more efficiently the ECM, CS has been often mixed to other natural and even synthetic polymers. Composites based on PCL, CS and collagen were used for bone-cartilage interface regeneration [116], 3D scaffolds made of CS, HA and collagen showed influence in proliferation and differentiation of chondrocytes [117].

Alginate-based biomaterials [118] have found application in nerve [119,120], bones [121], periodontal tissues [122] regeneration. It has also been reported that alginates of differing composition and purity induce rat bone marrow cells to proliferate or differentiate [123]. High purity alginate-calcium complexes, exhibiting a low immunogenic profile and easy gelation properties at physiological conditions, have been used to encapsulate pancreatic islets for immune protection [124].

PSA found application as coating material or scaffold for cell culture and peripheral nerve regeneration [125]. PSA is involved in several physiological processes like neural cell differentiation and organogenesis. Used alone or in combination with other polymers [126], PSA has been explored to induce the regeneration of nervous tissue, thanks to its effect in the modulation of the plasticity of neural cells [127]. The presence of PSA in synthetic cell microenvironments has been shown to improve both axon regeneration and the recruitment of progenitor cells [128].

\section{Natural glycosylation of ECM components}

The scaffold itself, although extremely important, is not sufficient to meet the complex requirements of nanomedicine tools.

It must interact with cells and properly induce and control their fate. GAGs are examples of high-molecular weight glycans providing signals that induce the cell fate, but also smaller oligosaccharides or even monosaccharides 
present in the ECM have a significant role in driving cell fate. The signals elicited by glycans are provided to the cells through interaction with specific carbohydrate receptors, generally defined lectins. They usually recognize a limited number of sugars residues (even just the terminal one), and very often the interaction is much more robust with multiple presentation (cluster effect). Table 2 reports examples of sugar epitopes and the parent receptors involved in mediation of several biological phenomena.

It is generally believed that the signaling glycans are expressed at the cell surface, whereas the glycocomponents of the ECM proteins have been neglected. Collagen, fibronectin, vitronectin, laminin and the other ECM proteins undergo dynamic glycosylation that depends on many and different factors such as age, pathologies and diet and strongly influences the cell fate [129-131].

\section{ECM protein glycosidation: effect on cell fate regulation}

$\mathrm{N}$-glycosylation of collagens and laminins influences the binding to integrin receptors on cell surface and it is strongly involved in pathological states and malignancies (i.e., several cancers). $N$-glycosylation of $\mathrm{Lm} 332$ is involved in the regulation of cell spreading, adhesion and migration [132]. $O$-glycosylation of fibronectin plays an important role during epithelial mesenchymal transition influencing cell motility and expression of mesenchymal markers [133]. Collagen I, for example, is overglycosylated in patients suffering from osteogenesis imperfecta, the hydroxylysine residues being more extensively galactosylated and subsequently glucosylated [Glc $\alpha(1-3) \mathrm{Gal} \beta-\mathrm{O}-]$ [134].

Glycosylation of ECM proteins are involved not just in cell-ECM interactions but also in the interaction with lectins in the extracellular space (i.e., galectins) and in the structural organization and functional role of the matrix itself $[135,136]$. The modifications of glycan expression on these proteins in ECM affect the functional role of cell microenvironment, by modulation and dysregulation of cell-ECM and ECM-ECM interactions. These are just a few examples of the importance of post-translational glycosylation of ECM components, but it is becoming clear that the glycocode at the extracellular level - more specifically the glyco-microrenvironment - can be exploited to induce specific cell fates for tissue engineering applications.

\section{Natural \& synthetic glycosylated biomaterials to mimic the glyco-microenvironment}

There are several examples in the literature in which mono-, di- and oligosaccharides have been used to decorate synthetic or natural bioactive materials to study the effect of glycans on cell fate regulation, in order to unravel the role of the glyco-microenvironment [137,138] (Figure 6).

Neoglycosylation of collagen has been performed by insertion of a thiol by reaction with thiobutyrolactone followed by thiol-ene reaction with $\alpha$-allyl-glucoside and $\beta$-allyl-galactoside, resulted in a biomaterial able to significantly promote motor functional recovery of the osteoarthritic rats [139]. A further relevant result was obtained culturing F11 neuroblastoma cells on collagen glycosylated by reductive amination with maltose. The exposed $\alpha-$ Glc residue induced not-functional F11 neuroblastoma cells to differentiate, inducing a neuritic-like process and restored the functional neuronal activity with the transmission of the electric signal [140]. Neoglycosylation of collagen also influences osteochondral regeneration, also using glycans that are not usually expressed in natural glycosylation pattern of collagen. In fact, it has been observed that residues of Neu 5aca2-3-Gal $\beta 1-4 \mathrm{Glc}-$ induce the upregulation of the expression of $A C A N$ and SOX9, markers of chondrogenesis, whereas residues of Neu5ac 2 26-Gal $\beta 1-4 \mathrm{Glc}-$ induce the upregulation of the expression of RUNX2 and $A L P$, markers of osteogenesis [141]. This result clearly indicates how a 'minor' variation in the glycan structure (linkage at position 6 instead of 3 ), significantly changes the cell fate.

Synthetic biomaterials (i.e., $\gamma$-PCL) have also been used as scaffold for glycosylated biomaterials, some of them have been investigated for liver tissue engineering or to improve mesenchymal stem cells adhesion on hydrophobic scaffolds $[142,143]$.

\section{Conclusions}

Glycans are definitively the most sophisticated signaling molecules developed by nature: their diversity (much higher of that one of peptides) and the dynamism of glycosylation as post-translational process allow them to affect the biological processes. Glycosylation is influenced by age, physiopathological states, diet and environmental changes. Glycosylated nanoparticles and nanomaterials have been successful employed until now in different pathological models for both therapeutic and diagnostic purposes. The generation of complex glycosylated nanotools, in order to target specific cell receptors, or to mimic tissues glycosignature, represents today a big challenge. 

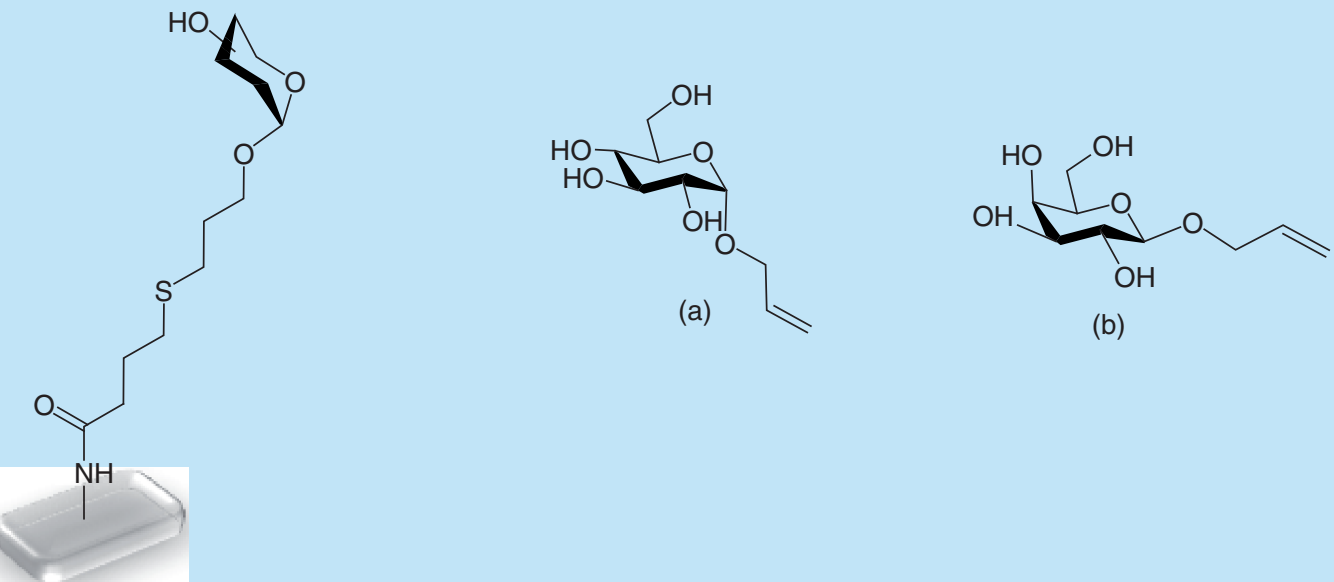

(b)

1. Collagen glycosylated by thiol-ene reaction

$\mathrm{R}-\mathrm{O}$

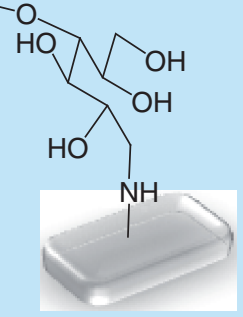

2. Collagen glycosylated by reductive amination

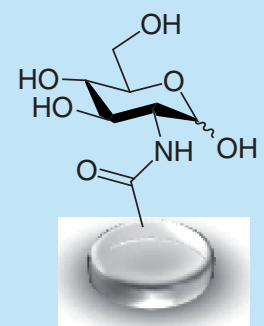

3. Polycaprolactone glycosylated by aminolysis

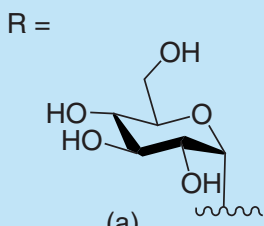

(a)<smiles>CC(C)(C)CCCCCC(=O)OC(C)(C)C</smiles>

PCL monomer

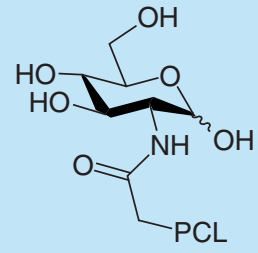

(a) one-step aminolysis with glucosamine

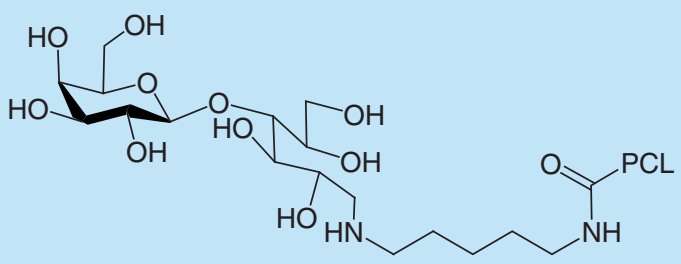

(b) two-step aminolysis with diamino linkers, followed by reductive amination

Figure 6. Neo-glycosylated biomaterials. (1). Collagen neoglycosylation, performed by insertion of a thiol and subsequent thiol-ene reaction with (a) $\alpha$-allyl-glucoside and (b) $\beta$-allyl-galactoside). (2). Collagen neoglycosylation by reductive amination with maltose, Neu5ac $\alpha 2-6-G a l \beta 1-4 G l c-$ and Neu5ac $\alpha 2-3-G a l \beta 1-4 G l c$ to expose (a) glucose, (b) Neu5ac $\alpha 2-6-G a l$ and (c) Neu5ac $\alpha 2-3-G a l$. (3). Polycaprolactose scaffolds (PCL glycosylated by aminolysis, (a) one-step procedure using glucosamine and (b) two-step procedure using hexanediaminolinker, followed by reductive amination with lactose.

PCL: Polycaprolactone. 


\section{Future perspective}

Understanding how glycosylation impacts in physiopathology, aging, environmental changes and lifestyles, and exploiting glyco-nano-tools to interact/interfere with such processes, is a very attractive perspective in personalized medicine. 'Dynamic' glyco-nano-tools, such as glycosylated-nanoparticles will represent a spot forwards for more efficient second generation drug-delivery systems, whereas 'static' glyco-nano-tools, such as nanostructured scaffolds mimicking the cell microenvironment, will allow to understand how dynamic glycosylation influences the cell fate, with relevant fallout in regenerative medicine and in understanding pathological processes and aging.

\section{Executive summary}

\section{Glycans in nanomedicine}

- Being glycans the biomolecules with highest structural diversity, employed by nature in a variety of selective recognition phenomena as well as structural and functional roles, nanomedicine exploits glycans as components of nanoparticles or nanostructured biomaterials and as molecular cues for selective interactions for targeting or to induce specific cell fates.

- Nanoparticles are used to build up drug-delivery systems or diagnostic tools.

- Biomaterials are mainly applied in regenerative medicine and tissue engineering as well as in cell culture.

Glycan-based nanoparticles

- Glycans find application in drug-delivery systems as autoassembling components of the nanoparticles.

- Charged polysaccharides can give rise to nanoparticles through electrostatic interactions, which can be also flanked by covalent cross-linking to modulate nanoparticle stability.

- On the other hand, desired nanoparticle collapse by exogenous or endogenous stimuli has been designed for controlled delivery purposes.

Glycan-coated nanoparticles

- Glycan-coated nanoparticles combine the advantageous properties of different materials together with the ability of carbohydrates to increase the biocompatibility of these systems or to target specific receptors.

- The nanoparticle coating with glycans makes them stealth to the immune system, avoiding their undesirable interactions, which can lead to a lack in therapeutic efficacy or even to toxic effects.

Targeting with glycan-decorated nanoparticles

- Both in healthy and pathological states, glycans mediate many biological recognition and signal transduction events, so they can be used as targeting agents.

Glyco-biomaterials

- Polysaccharides have been recognized as advantageous substrates to create novel scaffolds in regenerative process, marrying the characteristics of the biomaterials with cell requirements.

Natural glycosylation of extracellular matrix components

- Cell microenvironments are composed of proteins and glycans. It is becoming more and more evident that glycans provide signals inducing the cell fate.

Extracellular matrix protein glycosidation: effect on cell fate regulation

- The modifications of glycan expression on extracellular matrix (ECM) proteins, it is involved in the regulation cell functions. These phenomena are controlled by modulation of the interactions between cell-ECM and ECM-ECM.

Natural \& synthetic glycosylated biomaterials to mimic ECM components

- The observation that glycomicroenvironment is involved in the regulation of cell fate, opens the way to the development of synthetic glycosylated ECMs exploitable in regenerative medicine.

\section{Acknowledgment}

The authors acknowledge the graphic design support of Davide Perrone.

Financial \& competing interests disclosure

The authors acknowledge funding from the EC, H2020-MSCA-ITN-2014-GA-642028, Design and development of advanced NAnomedicines to overcome Biological BArriers and to treat severe diseases (NABBA) and H2020-NMBP-15-2017-GA-760986 Integration of Nano- and Biotechnology for beta-cell and islet Transplantation (iNanoBIT). The authors have no other relevant affiliations or financial involvement with any organization or entity with a financial interest in or financial conflict with the subject matter or materials discussed in the manuscript apart from those disclosed.

No writing assistance was utilized in the production of this manuscript. 


\section{Open access}

This work is licensed under the Attribution-NonCommercial-NoDerivatives 4.0 Unported License. To view a copy of this license, visit http://creativecommons.org/licenses/by-nc-nd/4.0/

\section{References}

Papers of special note have been highlighted as: $\bullet$ of interest; $\bullet \bullet$ of considerable interest

1. Gregoriadis G, Ryman BE. Liposomes as carriers of enzymes or drugs: a new approach to the treatment of storage diseases. Biochem. J. 124(5), 58P (1971).

2. Gregoriadis G. Drug entrapment in liposomes. FEBS Lett. 36, 292-296 (1973).

3. Gregoriadis G. The carrier potential of liposomes in biology and medicine. N. Engl. J. Med. 295, 765-770 (1976).

4. Mura S, Nicolas J, Couvreur P. Stimuli responsive nanocarriers for drug delivery. Nat. Mater. 12, 991-1003 (2013).

-. Gives a clear and systematic overview of the most significant stimuli-responsive drug-delivery nanocarriers, underlying the limits and challenges of each described strategy.

5. Mornet S, Vasseur S, Grasset F, Duguet E. Magnetic nanoparticle design for medical diagnosis and therapy. J. Mater. Chem. 14, 2161-2175 (2004).

6. Boisselier E, Astruc D. Gold nanoparticles in nanomedicine: preparations, imaging, diagnostics, therapies and toxicity. Chem. Soc. Rev. 38, 1759-1782 (2009).

7. Rolland J, Guillet P, Schumers JM, Duhem N, Préat V, Gohy JF. Polyelectrolyte complex nanoparticles from chitosan and poly(acrylic acid) and polystyrene-block-poly(acrylic acid). J. Polymer. Sci. A Polymer. Chem. 50, 4484-4493 (2012).

8. Santander-Ortega MJ, Stauner T, Loretz B et al. Nanoparticles made from novel starch derivatives for transdermal drug delivery. J. Control. Rel. 141(1), 85-92 (2010).

9. Wang X, Chen H, Luo Z, Fu X. Preparation of starch nanoparticles in water in oil microemulsion system and their drug-delivery properties. Carbohydr. Polym. 138, 192-200 (2016).

10. Dionísio M, Cordeiro C, Remunán-López C, Seijo B, Rosa Da Costa AM, Grenha A. Pullulan-based nanoparticles as carriers for transmucosal protein delivery. Eur. J. Pharm. Sci. 50(1), 102-113 (2013).

11. Wang JJ, Zeng ZW, Xiao RZ et al. Recent advances of chitosan nanoparticles as drug carriers. Int. J. Nanomedicine 6, 765-774 (2011).

12. Agnihotri SA, Mallikarjuna NN, Aminabhavi TM. Recent advances on chitosan-based micro- and nanoparticles in drug delivery. $J$. Control. Rel. 100(1), 5-28 (2004).

13. Grenha A. Chitosan nanoparticles: a survey of preparation methods. J. Drug. Target. 20(4), 291-300 (2012).

14. Paques JP, Van Der Linden E, Van Rijn CJ, Sagis LM. Preparation methods of alginate nanoparticles. Adv. Colloid Interface Sci. 209, 163-171 (2014).

15. Choi KY, Chung H, Min KH et al. Self-assembled hyaluronic acid nanoparticles for active tumor targeting. Biomaterials 31(1), 106-114 (2010).

16. Yang X, Du H, Liu J, Zhai G. Advanced nanocarriers based on heparin and its derivatives for cancer management. Biomacromolecules 16(2), 423-436 (2015).

17. Varghese OP, Liu J, Sundaram K, Hilborn J, Oommen OP. Chondroitin sulfate derived theranostic nanoparticles for targeted drug delivery. Biomater. Sci. 4(9), 1310-1313 (2016).

18. Zhao L, Liu M, Wang J, Zhai G. Chondroitin sulfate-based nanocarriers for drug/gene delivery. Carbohydr. Polym. 133, 391-399 (2015).

19. Burapapadh K, Takeuchi H, Sriamornsak P. Development of pectin nanoparticles through mechanical homogenization for dissolution enhancement of itraconazole. Asian J. Pharm. Sci. 11(3), 365-375 (2016).

20. Subudhi MB, Jain A, Jain A et al. Eudragit S100-coated citrus pectin nanoparticles for colon targeting of 5-fluorouracil. Materials (Basel) 8(3), 832-849 (2015).

21. Zhang Y, Chen T, Yuan P et al. Encapsulation of honokiol into self-assembled pectin nanoparticles for drug-delivery to HepG2 cells. Carbohydr. Polym. 133, 31-38 (2015).

22. Yudovin-Farber I, Domb AJ. Cationic polysaccharides for gene delivery. Mater. Sci. Eng. C 27, 595-598 (2007).

23. Azzam T, Eliyahu H, Makovitzki A, Linial M, Domb AJ. Hydrophobized dextran-spermine conjugate as potential vector for in vitro gene transfection. J. Control. Rel. 96(2), 309-323 (2004).

24. Tarvirdipour S, Vasheghani-Farahani E, Soleimani M, Bardania H. Functionalized magnetic dextran-spermine nanocarriers for targeted delivery of doxorubicin to breast cancer cells. Int. J. Pharm. 501(1-2), 331-341 (2016).

25. Tiyaboonchai W, Woiszwillo J, Russell Middaugh C. Formulation and characterization of DNA-polyethylenimine dextran sulfate nanoparticles. Eur. J. Pharm. Sci. 19(4), 91-202 (2003).

26. Ambattu LA, Rekha MR. Betaine conjugated cationic pullulan as effective gene carrier. Int. J. Biol. Macromol. 72, 819-826 (2015). 
27. Singh RS, Kaur N, Rana V, Kennedy JF. Pullulan: a novel molecule for biomedical applications. Carbohydr. Polym. 171, 102-121 (2017).

28. Deng X, Cao M, Zhang J et al. Hyaluronic acid-chitosan nanoparticles for co-delivery of MiR-34a and doxorubicin in therapy against triple negative breast cancer. Biomaterials 35(14), 4333-4344 (2014).

29. Oyarzun-Ampuero FA, Brea J, Loza MI, Torres D, Alonso MJ. Chitosan-hyaluronic acid nanoparticles loaded with heparin for the treatment of asthma. Int. J. Pharm. 381(2), 122-129 (2009).

30 . Lu HD, Zhao HQ, Wang K, Lv LL. Novel hyaluronic acid-chitosan nanoparticles as non-viral gene-delivery vectors targeting osteoarthritis. Int. J. Pharm. 420(2), 358-365 (2011).

31. De La Fuente M, Seijo B, Alonso MJ. Novel hyaluronic acid-chitosan nanoparticles for ocular gene therapy. Invest. Ophthalmol. Vis. Sci. 49(5), 2016-2024 (2008).

32. Chen YJ, Mohanraj VJ, Parkin JE. Chitosan-dextran sulfate nanoparticles for delivery of an anti-angiogenesis peptide. Lett. Pept. Sci. 10(5-6), 621-629 (2003).

33. Valente JFA, Gaspar VM, Antunes BP, Countinho P, Correia IJ. Microencapsulated chitosan-dextran sulfate nanoparticles for controled delivery of bioactive molecules and cells in bone regeneration. Polymer 54(1), 5-15 (2013).

34. Chaiyasan W, Srinivas SP, Tiyaboonchai W. Mucoadhesive chitosan-dextran sulfate nanoparticles for sustained drug-delivery to the ocular surface. J. Ocul. Pharmacol. Ther. 29(2), 200-207 (2013).

35. Sarmento B, Ribeiro A, Veiga F, Sampaio P, Neufeld R, Ferreira D. Alginate/chitosan nanoparticles are effective for oral insulin delivery. Pharm. Res. 24(12), 2198-2206 (2007).

36. Gazori T, Khoshayand MR, Azizi E, Yazdizade P, Nomani A, Haririan I. Evaluation of alginate/chitosan nanoparticles as antisense delivery vector: formulation, optimization and in vitro characterization. Carbohydr. Polym. 77(3), 599-606 (2009).

37. González-RodríGuez ML, Holgado MA, Sánchez-Lafuente C, Rabasco AM, Fini A. Alginate/chitosan particulate systems for sodium diclofenac release. Int. J. Pharm. 232(1-2), 225-234 (2002).

38. Liu Z, Jiao Y, Liu F, Zhang Z. Heparin/chitosan nanoparticle carriers prepared by polyelectrolyte complexation. J. Biomed. Mater. Res. A 83(3), 806-812 (2007).

39. Lin YH, Chang CH, Wu YS, Hsu YM, Chiou SF, Chen YJ. Development of pH-responsive chitosan/heparin nanoparticles for stomach-specific anti-Helicobacter pylori therapy. Biomaterials 30(19), 3332-3342 (2009).

40. Lin YH, Tsai SC, Lai CH, Lee CH, He ZS, Tseng GC. Genipin-cross-linked fucose-chitosan/heparin nanoparticles for the eradication of Helicobacter pylori. Biomaterials 34(18), 4466-4479 (2013).

41. Yuk SH, Oh KS, Cho SH et al. Enhancement of the targeting capabilities of the paclitaxel-loaded pluronic nanoparticles with a glycol chitosan/heparin composite. Mol. Pharm. 9(2), 230-236 (2012).

42. Santo VE, Gomes ME, Mano JF, Reis RL. Chitosan-chondroitin sulphate nanoparticles for controlled delivery of platelet lysates in bone regenerative medicine. J. Tissue Eng. Regen. Med. 6(Suppl. 3), 47-59 (2012).

43. Tsai HY, Chiu CC, Lin PC, Chen SH, Huang SJ, Wang LF. Antitumor efficacy of doxorubicin released from crosslinked nanoparticulate chondroitin sulfate/chitosan polyelectrolyte complexes. Macromol. Biosci. 11(5), 680-688 (2011).

44. Birch NP, Schiffman JD. Characterization of self-assembled polyelectrolyte complex nanoparticles formed from chitosan and pectin. Langmuir 30(12), 3441-3447 (2014).

45. Rampino A, Borgogna M, Bellich B, Blasi P, Virgilio F, Cesaro A. Chitosan-pectin hybrid nanoparticles prepared by coating and blending techniques. Eur. J. Pharm. Sci. 84, 37-45 (2016).

46. Csaba N, Koping-Hoggard M, Alonso MJ. Ionically crosslinked chitosan/tripolyphosphate nanoparticles for oligonucleotide and plasmid DNA delivery. Int. J. Pharm. 382(1-2), 205-214 (2009).

47. Wagner AM, Spencer DS, Peppas NA. Advanced architectures in the design of responsive polymers for cancer nanomedicine. J. Appl. Polym. Sci. 135(24), 46154 (2018).

48. Talelli M, Barz M, Rijcken CJ, Kiessling F, Hennink WE, Lammers T. Core-crosslinked polymeric micelles: principles, preparation, biomedical applications and clinical translation. Nano Today 10(1), 93-117 (2015).

49. Marradi M, Chiodo F, Garcia I, Penades S. Glyconanoparticles as multifunctional and multimodal carbohydrate systems. Chem. Soc. Rev. 42(11), 4728-4745 (2013).

- It describes the careful design of glycan-coated nanoparticles, correlating the synthetic factors to their effects on molecular recognition behaviors.

50. Zolnik BS, Gonzalez-Fernandez A, Sadrieh N, Dobrovolskaia MA. Nanoparticles and the immune system. Endocrinology 151(2), 458-465 (2010).

51. Ishida T, Wang XY, Shimizu T, Nawata K, Kiwada H. PEGylated liposomes elicit an anti-PEG IgM response in a T cell-independent manner. J. Control. Rel. 122(3), 349-355 (2007).

52. Gabizon A, Papahadjopoulos D. Liposome formulations with prolonged circulation time in blood and enhanced uptake by tumors. Proc. Natl Acad. Sci. USA 85(18), 6949-6953 (1988). 
53. Tassa C, Shaw SY, Weissleder R. Dextran-coated iron oxide nanoparticles: a versatile platform for targeted molecular imaging, molecular diagnostics, and therapy. ACC Chem. Res. 44(10), 842-852 (2011).

54. Jordan A, Scholz R, Maier-Hauff $\mathrm{K}$ et al. The effect of thermotherapy using magnetic nanoparticles on rat malignant glioma. J. Neurooncol. 78(1), 7-14 (2006).

55. Nath S, Kaittanis C, Tinkham A, Perez JM. Dextran-coated gold nanoparticles for the assessment of antimicrobial susceptibility. Anal. Chem. 80(4), 1033-1038 (2008).

56. Jang H, Ryoo SR, Kostarelos K, Han SW, Min DH. The effective nuclear delivery of doxorubicin from dextran-coated gold nanoparticles larger than nuclear pores. Biomaterials 34(13), 3503-3510 (2013).

57. Hifumi H, Yamaoka S, Tanimoto A et al. Dextran coated gadolinium phosphate nanoparticles for magnetic resonance tumor imaging. $J$. Mater. Chem. 19, 6393-6399 (2009).

58. Fuster MM, Esko JD. The sweet and sour of cancer: glycans as novel therapeutic targets. Nat. Rev. Cancer 5, 526-542 (2005).

59. Stahl PD, Ezekowitz RaB. The mannose receptor is a pattern recognition receptor involved in host defense. Curr. Opin. Immunol. 10(1), 50-55 (1998).

60. Schlepper-Schäfer J, Hülsmann D, Djovkar A et al. Endocytosis via galactose receptors in vivo: ligand size directs uptake by hepatocytes and/or liver macrophages. Exp. Cell Res. 165(2), 494-506 (1986).

61. Dumic J, Dabelic S, Flogel M. Galectin-3: an open-ended story. Biochim. Biophys. Acta 1760(4), 616-635 (2006).

62. Carrillo-Conde B, Song EH, Chavez-Santoscoy A et al. Mannose-functionalized 'pathogen-like' polyanhydride nanoparticles target C-type lectin receptors on dendritic cells. Mol. Pharm. 8(5), 1877-1886 (2011).

63. Tang CK, Lodding J, Minigo G et al. Mannan-mediated gene delivery for cancer immunotherapy. Immunology 120(3), 325-335 (2007).

64. Freichels $\mathrm{H}$, Wagner M, Okwieka P et al. (Oligo)mannose functionalized hydroxyethyl starch nanocapsules: en route to drug-delivery systems with targeting properties. J. Mater. Chem. B 1, 4338-4348 (2013).

65. Lin A, Liu Y, Huang Y et al. Glycyrrhizin surface-modified chitosan nanoparticles for hepatocyte-targeted delivery. Int. J. Pharm. 359(1-2), 247-253 (2008).

66. Nishikawa M, Yamauchi M, Morimoto K, Ishida E, Takakura Y, Hashida M. Hepatocyte-targeted in vivo gene expression by intravenous injection of plasmid DNA complexed with synthetic multi-functional gene-delivery system. Gene Ther. 7(7), 548-555 (2000).

67. Fiume L, Di Stefano G. Lactosaminated human albumin, a hepatotropic carrier of drugs. Eur. J. Pharm. Sci. 40(4), $253-262$ (2010).

68. Arosio D, Chiodo F, Reina JJ et al. Effective targeting of DC-SIGN by alpha-fucosylamide functionalized gold nanoparticles. Bioconjug. Chem. 25(12), 2244-2251 (2014).

69. Vedantam P, Tzeng TRJ, Brown AK, Podila R, Rao A, Staley K. Binding of Escherichia coli to functionalized gold nanoparticles. Plasmonics 7, 301-308 (2012).

70. Marradi M, Di Gianvincenzo P, Enriquez-Navas PM et al. Gold nanoparticles coated with oligomannosides of HIV-1 glycoprotein gp120 mimic the carbohydrate epitope of antibody 2G12. J. Mol. Biol. 410(5), 798-810 (2011).

71. Farr TD, Lai CH, Grunstein D et al. Imaging early endothelial inflammation following stroke by core-shell silica superparamagnetic glyconanoparticles that target selectin. Nano Lett. 14(4), 2130-2134 (2014).

72. Rhee JK, Baksh M, Nycholat C, Paulson JC, Kitagishi H, Finn MG. Glycan-targeted virus-like nanoparticles for photodynamic therapy. Biomacromolecules 13(8), 2333-2338 (2012).

73. Brinas RP, Sundgren A, Sahoo P et al. Design and synthesis of multifunctional gold nanoparticles bearing tumor-associated glycopeptide antigens as potential cancer vaccines. Bioconjug. Chem. 23(8), 1513-1523 (2012).

74. Boks MA, Ambrosini M, Bruijns SC et al. MPLA incorporation into DC-targeting glycoliposomes favours anti-tumour T cell responses. J. Control. Rel. 216, 37-46 (2015).

75. Fehres CM, Kalay H, Bruijns SC et al. Cross-presentation through langerin and DC-SIGN targeting requires different formulations of glycan-modified antigens. J. Control. Rel. 203, 67-76 (2015).

76. Park S, Kim GH, Park SH et al. Probing cell-surface carbohydrate binding proteins with dual-modal glycan-conjugated nanoparticles. $J$. Am. Chem. Soc. 137(18), 5961-5968 (2015).

77. Moros M, Hernaez B, Garet E et al. Monosaccharides versus PEG-functionalized NPs: influence in the cellular uptake. ACS Nano 6(2), 1565-1577 (2012).

- Describes an advanced pioneer work about the use of monosaccharides to create new theranostic agents.

78. Jiang X, Xin H, Ren Q et al. Nanoparticles of 2-deoxy-D-glucose functionalized poly(ethylene glycol)-co-poly(trimethylene carbonate) for dual-targeted drug-delivery in glioma treatment. Biomaterials 35(1), 518-529 (2014).

79. Chen WC, Completo GC, Sigal DS, Crocker PR, Saven A, Paulson JC. In vivo targeting of B-cell lymphoma with glycan ligands of CD22. Blood 115(23), 4778-4786 (2010).

80. El-Boubbou K, Zhu DC, Vasileiou C et al. Magnetic glyco-nanoparticles: a tool to detect, differentiate, and unlock the glyco-codes of cancer via magnetic resonance imaging. J. Am. Chem. Soc. 132(12), 4490-4499 (2010). 
81. Venturelli L, Nappini S, Bulfoni M et al. Glucose is a key driver for GLUT1-mediated nanoparticles internalization in breast cancer cells. Sci. Rep. 6, 21629 (2016).

82. O'Neil CL, Stine KJ, Demchenko AV. Immobilization of glycans on solid surfaces for application in glycomics. J. Carbohydr. Chem. 37(4), 225-249 (2018).

-• Gives a clear and systematic overview of the most significant progresses in glycoscience and materials applied to glycomics.

83. Shelke NB, James R, Laurencin CT, Kumbar SG. Polysaccharide biomaterials for drug-delivery and regenerative engineering. Polym. Adv. Technol. 25, 448-460 (2014).

-. The review clarifies the polysaccharides potential in regenerative engineering, outlining the mainly used carbohydrates in the field and furnishing a consistent number of applicative examples.

84. Francis Suh JK, Matthew HWT. Application of chitosan-based polysaccharide biomaterials in cartilage tissue engineering: a review. Biomaterials 21(24), 2589-2598 (2000).

85. Baldwin AD, Kiick KL. Polysaccharide-modified synthetic polymeric biomaterials. Biopolymers 94(1), 128-140 (2010).

86. Di Martino A, Sittinger M, Risbud MV. Chitosan: a versatile biopolymer for orthopaedic tissue-engineering. Biomaterials 26(30), 5983-5990 (2005).

87. Sgambato A, Cipolla L, Russo L. Bioresponsive hydrogels: chemical strategies and perspectives in tissue engineering. Gels 2(4), 28 (2016).

88. Muzzarelli RA, Greco F, Busilacchi A, Sollazzo V, Gigante A. Chitosan, hyaluronan and chondroitin sulfate in tissue engineering for cartilage regeneration: a review. Carbohydr. Polym. 89(3), 723-739 (2012).

89. Muller FA, Muller L, Hofmann I, Greil P, Wenzel MM, Staudenmaier R. Cellulose-based scaffold materials for cartilage tissue engineering. Biomaterials 27(21), 3955-3963 (2006).

90. Park MS, Joo W, Kim JK. Porous structures of polymer films prepared by spin coating with mixed solvents under humid condition. Langmuir 22(10), 4594-4598 (2006).

91. Bodhibukkana C, Srichana T, Kaewnopparat $S$ et al. Composite membrane of bacterially-derived cellulose and molecularly imprinted polymer for use as a transdermal enantioselective controlled-release system of racemic propranolol. J. Control. Rel. 113(1), 43-56 (2006).

92. Fu L, Zhang J, Yang G. Present status and applications of bacterial cellulose-based materials for skin tissue repair. Carbohydr. Polym. 92(2), 1432-1442 (2013).

93. Madihally SV, Matthew HWT. Porous chitosan scaffolds for tissue engineering. Biomaterials 20, 1133-1142 (1999).

94. Laurencin CT, Jiang T, Kumbar SG, Nair LS. Biologically active chitosan systems for tissue engineering and regenerative medicine. Curr. Top. Med. Chem. 8(4), 354-364 (2008).

95. Shi C, Zhu Y, Ran X, Wang M, Su Y, Cheng T. Therapeutic potential of chitosan and its derivatives in regenerative medicine. J. Surg. Res. 133(2), 185-192 (2006).

96. Logithkumar R, Keshavnarayan A, Dhivya S, Chawla A, Saravanan S, Selvamurugan N. A review of chitosan and its derivatives in bone tissue engineering. Carbohydr. Polym. 151, 172-188 (2016).

97. Cheng Y, Nada AA, Valmikinathan CM et al. In situ gelling polysaccharide-based hydrogel for cell and drug-delivery in tissue engineering. J. Appl. Polym. Sci. 131(4), 39934 (2014).

98. Jin R, Moreira Teixeira LS, Dijkstra PJ et al. Injectable chitosan-based hydrogels for cartilage tissue engineering. Biomaterials 30(13), 2544-2551 (2009).

99. Wedmore I, Mcmanus JG, Pusateri AE, Holcomb JB. A special report on the chitosan-based hemostatic dressing: experience in current combat operations. J. Trauma 60(3), 655-658 (2006).

100. Wedmore I, Mcmanus JG, Pusateri AE, Holcomb JB. The chitosan-based hemostatic dressing: experience in current combat operations. U.S. Army Med. Dep. J. 58 (2005).

101. Cheng Y, Ramos D, Lee P, Liang D, Yu X, Kumbar SG. Collagen functionalized bioactive nanofiber matrices for osteogenic differentiation of mesenchymal stem cells: bone tissue engineering. J. Biomed. Nanotechnol. 10(2), 287-298 (2014).

102. Wang D, Romer F, Connell L et al. Highly flexible silica/chitosan hybrid scaffolds with oriented pores for tissue regeneration. J. Mater. Chem. B 3, 7560-7576 (2015).

103. Kowitsch A, Zhou G, Groth T. Medical application of glycosaminoglycans: a review. J. Tissue Eng. Regen. Med. 12(1), e23-e41 (2018).

- Represents an excellent up-to-date review about glycosaminoglycans, their role in nature and their use in medical applications, moving from their use in pharmacology to treat a disease or a dysfunction to biological regeneration.

104. Murphy CM, Haugh MG, O'Brien FJ. The effect of mean pore size on cell attachment, proliferation and migration in collagen-glycosaminoglycan scaffolds for bone tissue engineering. Biomaterials 31(3), 461-466 (2010).

105. Pieper JS, Van Wachem PB, Van Luyn MJA et al. Attachment of glycosaminoglycans to collagenous matrices modulates the tissue response in rats. Biomaterials 21(16), 1689-1699 (2000).

106. Flanagan TC, Wilkins B, Black A, Jockenhoevel S, Smith TJ, Pandit AS. A collagen-glycosaminoglycan co-culture model for heart valve tissue engineering applications. Biomaterials 27(10), 2233-2246 (2006). 
107. Yan S, Zhang Q, Wang J et al. Silk fibroin/chondroitin sulfate/hyaluronic acid ternary scaffolds for dermal tissue reconstruction. Acta Biomater. 9(6), 6771-6782 (2013).

108. Nishinari K, Takahashi R. Interaction in polysaccharide solutions and gels. Curr. Opin. Colloid Interface Sci. 8(4-5), 396-400 (2003).

109. West DC, Kumar S. The biology of hyaluronan. In: Ciba Foundation Symposium 143. John Wiley \& Sons L, NY, USA, 187-207 (2007).

110. Noble PW, Lake FR, Henson PM, Riches DW. Hyaluronate activation of CD44 induces insulin-like growth factor-1 expression by a tumor necrosis factor-alpha-dependent mechanism in murine macrophages. J. Clin. Invest. 91(6), 2368-2377 (1993).

111. Suzuki K, Anada T, Miyazaki T et al. Effect of addition of hyaluronic acids on the osteoconductivity and biodegradability of synthetic octacalcium phosphate. Acta Biomater. 10(1), 531-543 (2014).

112. Prestwich GD. Hyaluronic acid-based clinical biomaterials derived for cell and molecule delivery in regenerative medicine. J. Control. Rel. 155(2), 193-199 (2011).

113. Burdick JA, Prestwich GD. Hyaluronic acid hydrogels for biomedical applications. Adv. Mater. 23(12), H41-H56 (2011).

114. Park J, Lim E, Back S, Na H, Park Y, Sun K. Nerve regeneration following spinal cord injury using matrix metalloproteinase-sensitive, hyaluronic acid-based biomimetic hydrogel scaffold containing brain-derived neurotrophic factor. J. Biomed. Mater. Res. A 93(3), 1091-1099 (2010).

115. Mohd Isa IL, Abbah SA, Kilcoyne M et al. Implantation of hyaluronic acid hydrogel prevents the pain phenotype in a rat model of intervertebral disc injury. Sci. Adv. 4(4), doi: 10.1126/sciadv.aaq0597 (2018).

116. Baier Leach J, Bivens KA, Patrick CW Jr, Schmidt CE. Photocrosslinked hyaluronic acid hydrogels: natural, biodegradable tissue engineering scaffolds. Biotechnol. Bioeng. 82(5), 578-589 (2003).

117. Ko CS, Huang JP, Huang CW, Chu IM. Type II collagen-chondroitin sulfate-hyaluronan scaffold cross-linked by genipin for cartilage tissue engineering. J. Biosci. Bioeng. 107(2), 177-182 (2009).

118. Lee KY, Mooney DJ. Alginate: properties and biomedical applications. Prog. Polym. Sci. 37(1), 106-126 (2012).

119. Suzuki Y, Tanihara M, Ohnishi K, Suzuki K, Endo K, Nishimura Y. Cat peripheral nerve regeneration across 50 mm gap repaired with a novel nerve guide composed of freeze-dried alginate gel. Neurosci. Lett. 259(2), 75-78 (1999).

120. Alsberg E, Anderson KW, Albeiruti A, Franceschi RT, Mooney DJ. Cell-interactive alginate hydrogels for bone tissue engineering. J. Dent. Res. 80(11), 2025-2029 (2001).

121. Ueyama Y, Ishikawa K, Mano T et al. Usefulness as guided bone regeneration membrane of the alginate membrane. Biomaterials 23(9), 2027-2033 (2002).

122. Srinivasan S, Jayasree R, Chennazhi KP, Nair SV, Jayakumar R. Biocompatible alginate/nano bioactive glass ceramic composite scaffolds for periodontal tissue regeneration. Carbohydr. Polym. 87, 274-283 (2012).

123. Wang L, Shelton RM, Cooper PR, Lawson M, Triffitt JT, Barralet JE. Evaluation of sodium alginate for bone marrow cell tissue engineering. Biomaterials 24(20), 3475-3481 (2003).

124. Strand BL, Coron AE, Skjak-Braek G. Current and future perspectives on alginate encapsulated pancreatic islet. Stem Cells Transl. Med. 6(4), 1053-1058 (2017).

125. Stark Y, Bruns S, Stahl F et al. A study on polysialic acid as a biomaterial for cell culture applications. J. Biomed. Mater. Res. A 85(1), 1-13 (2008).

126. Zhang S, Wang XJ, Li WS et al. Polycaprolactone/polysialic acid hybrid, multifunctional nanofiber scaffolds for treatment of spinal cord injury. Acta Biomater. doi:10.1016/j.actbio.2018.06.038 (2018) (Epub ahead of print).

127. Rutishauser U. Polysialic acid in the plasticity of the developing and adult vertebrate nervous system. Nat. Rev. Neurosci. 9(1), 26-35 (2008).

128. Gascon E, Vutskits L, Kiss JZ. Polysialic acid-neural cell adhesion molecule in brain plasticity: from synapses to integration of new neurons. Brain Res. Rev. 56(1), 101-118 (2007).

129. Freire-De-Lima L. Sweet and sour: the impact of differential glycosylation in cancer cells undergoing epithelial-mesenchymal transition. Front. Oncol. 4, 59 (2014).

130. Uematsu S, Goto Y, Suzuki T, Sasazawa Y, Dohmae N, Simizu S. N-Glycosylation of extracellular matrix protein 1 (ECM1) regulates its secretion, which is unrelated to lipoid proteinosis. FEBS Open Bio 4, 879-885 (2014).

131. Niu Y, Xie T, Ge K, Lin Y, Lu S. Effects of extracellular matrix glycosylation on proliferation and apoptosis of human dermal fibroblasts via the receptor for advanced glycosylated end products. Am. J. Dermatopathol. 30(4), 344-351 (2008).

132. Kariya Y, Kato R, Itoh S et al. N-Glycosylation of laminin-332 regulates its biological functions. A novel function of the bisecting GlcNAc. J. Biol. Chem. 283(48), 33036-33045 (2008).

133. Marsico G, Russo L, Quondamatteo F, Pandit A. Glycosylation and integrin regulation in cancer. Trends Cancer 4(8), 537-552 (2018).

134. Taga Y, Kusubata M, Ogawa-Goto K, Hattori S. Site-specific quantitative analysis of overglycosylation of collagen in osteogenesis imperfecta using hydrazide chemistry and SILAC. J. Proteome Res. 12(5), 2225-2232 (2013). 
135. Zamze S, Harvey DJ, Pesheva P et al. Glycosylation of a CNS-specific extracellular matrix glycoprotein, tenascin-R, is dominated by O-linked sialylated glycans and 'brain-type' neutral N-glycans. Glycobiology 9(8), 823-831 (1999).

136. Lynch M, Barallobre-Barreiro J, Jahangiri M, Mayr M. Vascular proteomics in metabolic and cardiovascular diseases. J. Intern. Med. 280(4), 325-338 (2016).

137. Russo L, Cipolla L. Glycomics: new challenges and opportunities in regenerative medicine. Chemistry 22(38), 13380-13388 (2016).

138. Bojarova P, Kren V. Sugared biomaterial binding lectins: achievements and perspectives. Biomater. Sci. 4(8), 1142-1160 (2016).

139. Russo L, Battocchio C, Secchi V et al. Thiol-ene mediated neoglycosylation of collagen patches: a preliminary study. Langmuir 30(5), 1336-1342 (2014).

140. Russo L, Sgambato A, Lecchi M et al. Neoglucosylated collagen matrices drive neuronal cells to differentiate. ACS Chem. Neurosci. 5(4), 261-265 (2014).

141. Sgambato A, Russo L, Montesi M et al. Different sialoside epitopes on collagen film surfaces direct mesenchymal stem cell fate. ACS Appl. Mater. Interfaces 8(24), 14952-14957 (2016).

142. Cho CS, Seo SJ, Park IK et al. Galactose-carrying polymers as extracellular matrices for liver tissue engineering. Biomaterials 27(4), 576-585 (2006).

143. Russo L, Gloria A, Russo T et al. Glucosamine grafting on poly( $\epsilon$-caprolactone): a novel glycated polyester as a substrate for tissue engineering. RSC Adv. 3(18), 6286-6289 (2013). 